\title{
Prefrontal Cortical Kappa-Opioid Receptor Modulation of Local Neurotransmission and Conditioned Place Aversion
}

\author{
Hugo A Tejeda*,',2, Danielle S Counotte², Eric Oh', Sammanda Ramamoorthy ${ }^{3}$, \\ Kristin N Schultz-Kuszak', Cristina M Bäckman', Vladmir Chefer', Patricio O’Donnell ${ }^{2,4}$ and \\ Toni S Shippenberg'
}

IIntegrative Neuroscience Section, Integrative Neuroscience Branch, National Institute on Drug Abuse, Baltimore, MD, USA; ${ }^{2}$ Department of Anatomy and Neurobiology, University of Maryland School of Medicine, Baltimore, MD, USA; ${ }^{3}$ Department of Neurosciences, Division of Neuroscience Research Medical University of South Carolina, Charleston, SC, USA; ${ }^{4}$ Department of Psychiatry, University of Maryland School of Medicine, Baltimore, MD, USA

Kappa-opioid receptors (KORs) are important for motivation and other medial prefrontal cortex (mPFC)-dependent behaviors. Although KORs are present in the MPFC, their role in regulating transmission in this brain region and their contribution to KOR-mediated aversion are not known. Using in vivo microdialysis in rats and mice, we demonstrate that intra-mPFC administration of the selective KOR agonist U69,593 decreased local dopamine (DA) overflow, while reverse dialysis of the KOR antagonist nor-Binaltorphimine (nor-BNI) enhanced mPFC DA overflow. Extracellular amino-acid levels were also affected by KORs, as U69,593 reduced glutamate and GABA levels driven by the glutamate reuptake blocker, I-trans-pyrrolidine-2,4-dicarboxylate. Whole-cell recordings from mPFC layer $V$ pyramidal neurons revealed that U69,593 decreased the frequency, but not amplitude, of glutamatergic mini EPSPs. To determine whether KOR regulation of mPFC DA overflow was mediated by KOR on DA terminals, we utilized a Cre recombinase-driven mouse line lacking KOR in DA neurons. In these mice, basal DA release or uptake was unaltered relative to controls, but attenuation of mPFC DA overflow by local U69,593 was not observed, indicating KOR acts directly on mPFC DA terminals to locally inhibit DA levels. Conditioning procedures were then used to determine whether mPFC KOR signaling was necessary for KOR-mediated aversion. U69,593-mediated conditioned place aversion was blocked by intra-mPFC nor-BNI microinjection. These findings demonstrate that mPFC KORs negatively regulate DA and amino-acid neurotransmission, and are necessary for KOR-mediated aversion. Neuropsychopharmacology (2013) 38, 1770-1779; doi:I0.1038/npp.2013.76; published online 24 April 2013

Keywords: kappa-opioid receptors; prefrontal cortex; dopamine; GABA; glutamate; aversion

\section{INTRODUCTION}

The endogenous kappa-opioid receptor (KOR) system is implicated in motivation, mood, and stress-related behaviors (Shippenberg et al, 2007; Bruchas et al, 2010; Knoll and Carlezon, 2010; Tejeda et al, 2012). Synthetic and naturally occurring KOR agonists produce psychotomimetic and anxiogenic effects in humans (Pfeiffer et al, 1986; Walsh et al, 2001). They decrease brain reward function and produce conditioned aversive effects in rodents (Mucha and Herz, 1985; Todtenkopf et al, 2004). KOR-mediated aversion may involve modulation of monoamine systems, including the mesolimbic dopamine (DA) pathway, and is a useful behavioral model of mood control of behavior. Mesolimbic, but not mesocortical, 6-OHDA lesions or

*Correspondence: $\mathrm{H}$ Tejeda, Department of Anatomy and Neurobiology, University of Maryland School of Medicine, 20 Penn Street, room S-25I, Baltimore, MD 2120I, USA. Tel: + I 4107066412 , Fax: + 410706 25I2, E-mail: tejedah@nida.nih.gov Received 2 January 2013; revised 6 March 2013; accepted 21 March 2013; accepted article preview online 29 March 2013 nucleus accumbens (NAcc) DA D1 receptor blockade abolish conditioned place aversion (CPA) produced by systemically administered KOR agonists (Shippenberg et al, 1993). These data suggest that modulation of mesocortical DA transmission by KORs is not necessary for KORmediated CPA. However, anatomical mapping studies demonstrated that medial prefrontal cortex (mPFC) KOR activation is sufficient to produce CPA, pointing to the mPFC as a putative locus of KOR-mediated aversion (BalsKubik et al, 1993). Thus, it remains to be determined whether mPFC KOR signaling is necessary for KORmediated aversion.

Although there is strong evidence for an inhibitory role of KORs in regulating mesolimbic DA neurotransmission, little is known about their role in regulating mPFC DA neurotransmission. KORs directly inhibit mesocortical DA neurons thereby reducing mPFC DA overflow (Margolis et al, 2006). However, whether MPFC KORs modulate extracellular DA dynamics in vivo has not been studied. In the mPFC, KOR immunoreactivity is present in monoamine axonal varicosities and presynaptic terminals of asymmetric and symmetric synapses (Svingos and Colago, 2002), 
providing an anatomical framework for mPFC KOR systems to locally regulate DA and amino-acid neurotransmission. Here, we assessed whether $\mathrm{mPFC}$ KORs regulate DA, GABA, and glutamate transmission using a combination of in vivo microdialysis, whole-cell recordings, and conditional knock-out of KOR in DA neurons in mice. We also assessed the contribution of $\mathrm{mPFC}$ KORs to the conditioned aversive effects of a systemically administered KOR agonist.

\section{MATERIALS AND METHODS}

\section{Subjects}

Adult male Sprague-Dawley rats (Charles River) weighing 300-400 g (> PND 60) were utilized. For conditional knockout of KOR in DA neurons, we utilized a DAT promoterdriven Cre transgenic mouse line (DAT ${ }^{\mathrm{Cre}}$; Slc6a3Cre; (Backman et al, 2006)) and $\mathrm{KOR}^{\operatorname{lox} \mathrm{P}}$ mice (Dr Jennifer Whistler; University of California, San Francisco, CA, USA). $\mathrm{DAT}^{\mathrm{Cre}}$ and $\mathrm{KOR}^{\text {loxP }}$ mice maintained on a pure C57BL/6J background were cross bred to obtain control mice $\left(\mathrm{DAT}^{\mathrm{Cre} / \mathrm{wt}} ; \mathrm{KOR}^{\mathrm{wt} / \mathrm{wt}}\right.$ ) and knock-out mice lacking KOR in DA neurons: DAT-KOR KO mice (DAT ${ }^{\mathrm{Cre} / \mathrm{wt}}$; $\mathrm{KOR}^{\text {loxP/loxP }}$ ). $\mathrm{KOR}^{\text {loxp }}$ mice were generated by flanking Exon 2, containing the start codon, of the Oprk1 gene with loxp sequences. $\mathrm{DAT}^{\mathrm{Cre}}$ mice were generated by inserting an internal ribosome entry-linked Cre recombinase gene downstream from the Slc6a3 gene stop codon. Both mouse strains were in congenic C57BL/6 background at the time of crossbreeding. KOR knock-out in DAT-expressing neurons was confirmed by PCR analysis of DNA from olfactory bulb and VTA/substantia nigra tissue, and was absent in cortex, striatum, or cerebellum (Supplementary Methods; Supplementary Figure S1). Additionally, double fluorescent in situ hybridization (FISH) was performed to determine the specificity of the mutation in the SN/VTA region. Adult male mice (20-30 g; > PND 60) were housed in temperature- and humidity-controlled facilities accredited by the American Association for the Accreditation of Laboratory Animal Care under a 12-h light/dark cycle with ad-libitum chow and water. Experiments were conducted in accordance with the guidelines of the Institutional Care and Use Committee of the National Institute on Drug Abuse (NIDA), University of Maryland, Baltimore, and Medical University of South Carolina.

\section{Surgery}

Rats were anesthetized with Equithesin (1\% pentobarbital, $2 \%$ magnesium sulfate, $4 \%$ chloral hydrate, $42 \%$ propylene glycol, $11 \%$ ethanol) and implanted with a unilateral microdialysis guide cannula (CMA11; CMA microdialysis) or bilateral microinjection guide cannulas (C235G; plastics one) aimed at the mPFC ( $+3.2 \mathrm{~mm}(\mathrm{AP}) ; \pm 0.6 \mathrm{~mm}(\mathrm{ML})$; 2.3 and $2.2 \mathrm{~mm}$ from brain surface (DV) for microdialysis and microinjection experiments, respectively; Paxinos and Watson (1998)). A subset of rats was implanted with an intra-jugular vein catheter and a $\mathrm{MPFC}$ unilateral microdialysis guide cannula. Mice were anaesthetized with ketamine ( $80 \mathrm{mg} / \mathrm{kg}$; i.p.) and xylazine ( $8 \mathrm{mg} / \mathrm{kg}$; i.p.) and implanted with a unilateral microdialysis guide cannula aimed at the mPFC (CMA7; CMA microdialysis; AP +1.8 to
$1.9 \mathrm{~mm}$; ML: $-0.3 \mathrm{~mm}$; DV: $-1.75 \mathrm{~mm}$; Paxinos and Franklin (2001)).

\section{In vivo Microdialysis}

Animals recovered from surgery for 5-7 days before dialysis. Before testing $(\sim 14 \mathrm{~h})$, a microdialysis probe (CMA/11; $0.24 \times 3 \mathrm{~mm}$ membrane for rat; CMA/7; $0.24 \times 2 \mathrm{~mm}$ membrane for mouse; CMA Microdialysis) was inserted through the guide cannula. Probes were perfused with aCSF overnight (145 mM NaCl, $2.8 \mathrm{mM} \mathrm{KCl}$, $1.2 \mathrm{mM} \mathrm{MgCl}_{2}, 1.2 \mathrm{mM} \mathrm{CaCl}_{2}, 5.4 \mathrm{mM}$ glucose, $\mathrm{pH}$ 7.2-7.4; $0.3 \mu \mathrm{l} / \mathrm{min}$; CMA102 syringe pump; CMA microdialysis). The following day, fresh aCSF was pumped $(0.6 \mu \mathrm{l} / \mathrm{min})$. Following a $2 \mathrm{~h}$ equilibration period, four to six 10 (amino acids) or 15 (DA) min baseline samples were collected before experimental manipulation. To examine the effects of systemic U69,593 administration on mesocortical DA transmission, rats were challenged with repeated intravenous vehicle injections (heparinized saline, $\mathrm{pH} 7.2-7.4$ ) or a vehicle injection followed by escalating doses of U69,593 $(0.02$ and $0.04 \mathrm{mg} / \mathrm{kg})$. To examine the role of $\mathrm{mPFC}$ KOR in regulating local neurotransmission, perfusate containing U69,593 (0.5 and $1.0 \mu \mathrm{M})$, nor-BNI $(0.5$ and $1.0 \mu \mathrm{M})$, DAMGO $(100 \mu \mathrm{M})$, and/or l-trans-pyrrolidine-2,4-dicarboxylate (tPDC; $1 \mathrm{mM}$ ) were administered via reverse dialysis. During no-net-flux microdialysis experiments five different concentrations of DA were included in the perfusate $\left(D A_{\text {in }}\right.$ : $0,1.25,2.5,5$, and $10 \mathrm{nM})$ in a pseudo-random order to determine extracellular DA (DA $\mathrm{DAt}_{\mathrm{ex}} ; x$ intercept) and extraction fraction $\left(E_{\mathrm{d}}\right.$; slope), an indicator of DA uptake. Three 15 min samples were collected at each $D A_{\text {in }}$ concentration to determine DA in the dialysate $\left(D A_{\text {out }}\right)$.

\section{High Performance Liquid Chromatography}

Dialysate DA concentrations were analyzed using high performance liquid chromatography (HPLC) with electrochemical detection (see supplementary Methods (Chefer et al, 2005)). Dialysates were injected into either a BAS HPLC system (Bioanalytical Systems) consisting of a BASPhase II HPLC column, a BAS PM-92e HPLC pump, and a BAS LC-4C amperometric detector or an Eicom HTEC-500 HPLC system with an integrated amperometric detector, consisting a PP-ODS HPLC column and a HTEC-500 pump.

\section{Capillary Electrophoresis with Laser-Induced Fluorescence}

GABA and glutamate dialysate concentrations were estimated using a capillary electrophoresis P/ACE MDQ system (Beckman, USA) coupled to an external ZETALIF laserinduced fluorescence detector (Picometrics, France), as previously described (see Supplementary Methods; (Chefer et al, 2009)). The capillary $(50 \mu \mathrm{m}$ ID, $350 \mu \mathrm{m}$ OD, Polymicro Technologies; $62 \mathrm{~cm}$ long; $46 \mathrm{~cm}$ to detection window) was loaded with $0.020 \mu \mathrm{l}$ of sodium cyanide (300 mM, pH 10.5) and $0.040 \mu \mathrm{l}$ of naphthalene-2,3-dicarboxaldehyde $(15 \mathrm{mM})$. Then, $0.33 \mu \mathrm{l}$ of the contents were delivered into the dialysate $(2.0 \mu \mathrm{l})$. After $5 \mathrm{~min}$ of derivatization, separation in running buffer was achieved by applying a $24-\mathrm{kV}$ potential $\left(33^{\circ} \mathrm{C}\right)$. Fluorophore 
excitation was achieved via a laser diode (Picometrics; $410 \mathrm{~nm}$ excitation; $490 \mathrm{~nm}$ emission).

\section{$\left[{ }^{3} \mathrm{H}\right]$ DA Uptake}

Rats were decapitated, and mPFC was dissected and obtained for $\left[{ }^{3} \mathrm{H}\right]$ DA uptake assays as previously described (Supplementary Methods; (Zapata et al, 2007)). mPFC synaptosomes $(30 \mu \mathrm{g})$ were incubated in $0.3 \mathrm{ml}$ of KrebsRinger-HEPES buffer containing $0.1 \mathrm{mM}$ ascorbic acid, and $0.1 \mathrm{mM}$ pargyline in the presence of vehicle or $\mathrm{U} 69,593$ at $37^{\circ} \mathrm{C}$. Uptake was initiated by the addition of $40 \mathrm{nM}\left[{ }^{3} \mathrm{H}\right]$ $\mathrm{DA}$ and terminated after $5 \mathrm{~min}$.

\section{Electrophysiology}

Young adult male Sprague-Dawley rats (200-300 g; > PND 50) were anesthetized with chloral hydrate $(400 \mathrm{mg} / \mathrm{kg}$, i.p.) and decapitated for whole-cell recording of layer $\mathrm{V}$ pyramidal neurons (Supplementary Methods). Brains were removed into ice-cold aCSF $\left(95 \% \mathrm{O}_{2}-5 \% \mathrm{CO}_{2}\right)$ containing: $125 \mathrm{mM} \mathrm{NaCl}, 25 \mathrm{mM} \mathrm{NaHCO}_{3}, 10 \mathrm{mM}$ glucose, $3.5 \mathrm{mM} \mathrm{KCl}$, $1.25 \mathrm{mM} \mathrm{NaH}_{2} \mathrm{PO}_{4}, 0.5 \mathrm{mM} \mathrm{CaCl}$, and $3 \mathrm{mM} \mathrm{MgCl} 2(\mathrm{pH}$ 7.45, 295-300 mOsm). Coronal slices $(300 \mu \mathrm{m})$ containing the $\mathrm{mPFC}$ were obtained in ice-cold aCSF and incubated in $95 \% \mathrm{O}_{2}-5 \% \mathrm{CO}_{2}$ aCSF $\left(\sim 35^{\circ} \mathrm{C}\right)$ solution for $45 \mathrm{~min}$ before recording. Patch electrodes (6-9M $\Omega$ ) were filled with $0.125 \%$ Neurobiotin, $115 \mathrm{mM}$ K-gluconate, $10 \mathrm{mM}$ HEPES, $2 \mathrm{mM} \mathrm{MgCl} 2,20 \mathrm{mM} \mathrm{KCl}, 2 \mathrm{mM} \mathrm{MgATP}, 2 \mathrm{mM} \mathrm{Na}_{2}$-ATP, and $0.3 \mathrm{mM}$ GTP (pH 7.25-7.30; $280-285 \mathrm{mOsm}$ ). Wholecell current-clamp recordings were performed with a computer-controlled amplifier (Multiclamp 700A), digitized (Digidata 1322), and acquired with Axoscope 9 (Molecular Devices; $10 \mathrm{kHz}$ sampling rate). Baseline activity was monitored for 10 min during which membrane potential and input resistance were measured, before recording $2 \mathrm{~min}$ of miniature excitatory post-synaptic potentials (mEPSPs) in the presence of tetrodotoxin (TTX) and presence or absence of picrotoxin or nor-BNI $(0.1 \mu \mathrm{M})$. U69,593containing aCSF was superfused for $10 \mathrm{~min}$ before recording 2 min of mEPSPs.

\section{Conditioned Place Aversion}

Conditioning procedures were carried out using an apparatus consisting of two discrete Plexiglas chambers connected by a smaller, gray center chamber (see Supplementary Methods). mPFC bilateral guide cannulas were implanted 4-5 days before conditioning procedures (see Figure 5). During the pre-test, rats were given free access to all compartments for $15 \mathrm{~min}$ and time spent in each compartment was recorded. Four-six hours after the pre-test, $0.5 \mu \mathrm{l}$ aCSF or nor-BNI $(5.0 \mu \mathrm{g} / 0.5 \mu \mathrm{l})$ was bilaterally injected into the mPFC. Nor-BNI has been shown to produce long-lasting behavioral effects that persist for weeks after administration (Endoh et al, 1992). The subsequent day, rats were injected with vehicle or U69,593 $(0.32 \mathrm{mg} / \mathrm{kg}$; s.c. $)$ and immediately confined to their initially preferred compartment for $45 \mathrm{~min}$. On alternate days, rats were injected with vehicle and confined in their nonpreferred compartment. This 2-day procedure was repeated three times over six consecutive days. During the post-test, rats were allowed access to all compartments and tested for their preference for $15 \mathrm{~min}$.

\section{Drugs}

U69,593, nor-BNI, and DAMGO were supplied by the Research Technology Branch of NIDA (Rockville, MD, USA). Stock solutions of U69,593 (10 mM) were dissolved in $0.1 \mathrm{~N} \mathrm{HCl}$ and diluted in either sterile saline or aCSF (pH 7.2-7.4 with $\mathrm{NaOH}$ ). Nor-BNI and tPDC (Tocris) were dissolved in aCSF. Concentrations of U69,593 and nor-BNI used in the present study have been previously used (Lemos et al, 2012; Hjelmstad and Fields, 2001, 2003; Margolis et al, 2003; Margolis et al, 2003, 2006; Iremonger and Bains, 2009; Mu et al, 2011).

\section{Histology}

Brains were removed, frozen, and sectioned $(40 \mu \mathrm{m})$. Histological verification of the microdialysis probe location in rats and mice (Supplementary Figure S2) and microinjection cannula tips (Figure 5A) was obtained from coronal sections.

\section{Statistical Analysis}

Results were analyzed using repeated measures ANOVA, one-way ANOVA, or Student's $t$-test, where appropriate. Post-hoc analyses were carried out using Fisher's LSD test or a paired $t$-test. Area under the curve (AUC) values were obtained using the standard trapezoidal method. A-priori planned comparisons were carried out utilizing a paired or Student's $t$-test with Bonferroni correction for CPA experiments ( $n=3$ to prevent type I errors).

\section{RESULTS}

For in vivo microdialysis experiments, microdialysis probe membranes spanned anterior cingulate, prelimbic, and inframlimbic cortexes in rats and mice (Supplementary Figure S2).

\section{Systemic Administration of the Selective KOR Agonist U69,593 Decreases Extracellular DA Levels}

Acute intravenous administration of U69,593 decreased mPFC DA overflow in rats (Figure 1). Analysis of DA levels revealed a main effect of sample-type (baseline, vehicle infusion, $\mathrm{U} 69,593$ infusion; $\left.\mathrm{F}_{(3,66)}=10.09 ; P<0.001\right)$, no main effect of treatment (controls treated with repeated vehicle vs U69,593-treated; $\left.\mathrm{F}_{(1,11)}=4.02 ; P=0.07\right)$ and a significant sample-type $\mathrm{x}$ treatment interaction $\left(\mathrm{F}_{(3,66)}=4.38 ; P=0.011\right.$; Figure $1 \mathrm{~b}$ ). AUC analysis (of the three samples corresponding to the each challenge) also revealed a main effect of sample-type $\left(\mathrm{F}_{(2,22)}=12.21\right.$; $P<0.01)$, no main effect of treatment $\left(\mathrm{F}_{(1,11)}=1.32\right.$; $P=00.27)$, and a significant sample-type $\mathrm{x}$ treatment interaction $\left(\mathrm{F}_{(2,22)}=5.47 ; P=0.03\right.$; Figure 1c). Post-hoc analysis revealed a significant decrease in DA after administration of $0.04 \mathrm{mg} / \mathrm{kg} \mathrm{U} 69,593$ relative to vehicle administration $(P<0.05)$ and vehicle-treated control rats $(P<0.05)$. 


\section{mPFC KORs Tonically Inhibit Local DA Overflow}

Reverse dialysis of U69,593 decreased mPFC DA levels in rats (Figure 1c and d). ANOVA revealed a main effect of sample-type (baseline, U69,593 infusion, washout; $\left.\mathrm{F}_{(2,78)}=14.88 ; P<0.001\right)$, no main effect of dose $(0,0.5$, $\left.1.0 \mu \mathrm{M} ; \mathrm{F}_{(1,13)}=0.17 ; P=0.84\right)$, and a sample-type $\mathrm{x}$ dose interaction $\left(\mathrm{F}_{(4,78)}=6.15 ; P<0.01\right.$; Figure 1c). AUC (of the first three U69,593 samples) comparisons indicated an effect of dose $\left(\mathrm{F}_{(2,22)}=8.021 ; P=0.01\right.$; Figure 1d). Post-hoc analysis demonstrated that intra-mPFC U69,593 (0.5 and $1.0 \mu \mathrm{M})$ administration decreased DA levels relative to aCSF controls $(P<0.01)$.

Reverse dialysis of the KOR antagonist nor-BNI significantly enhanced basal dialysate DA levels in rats. Repeated
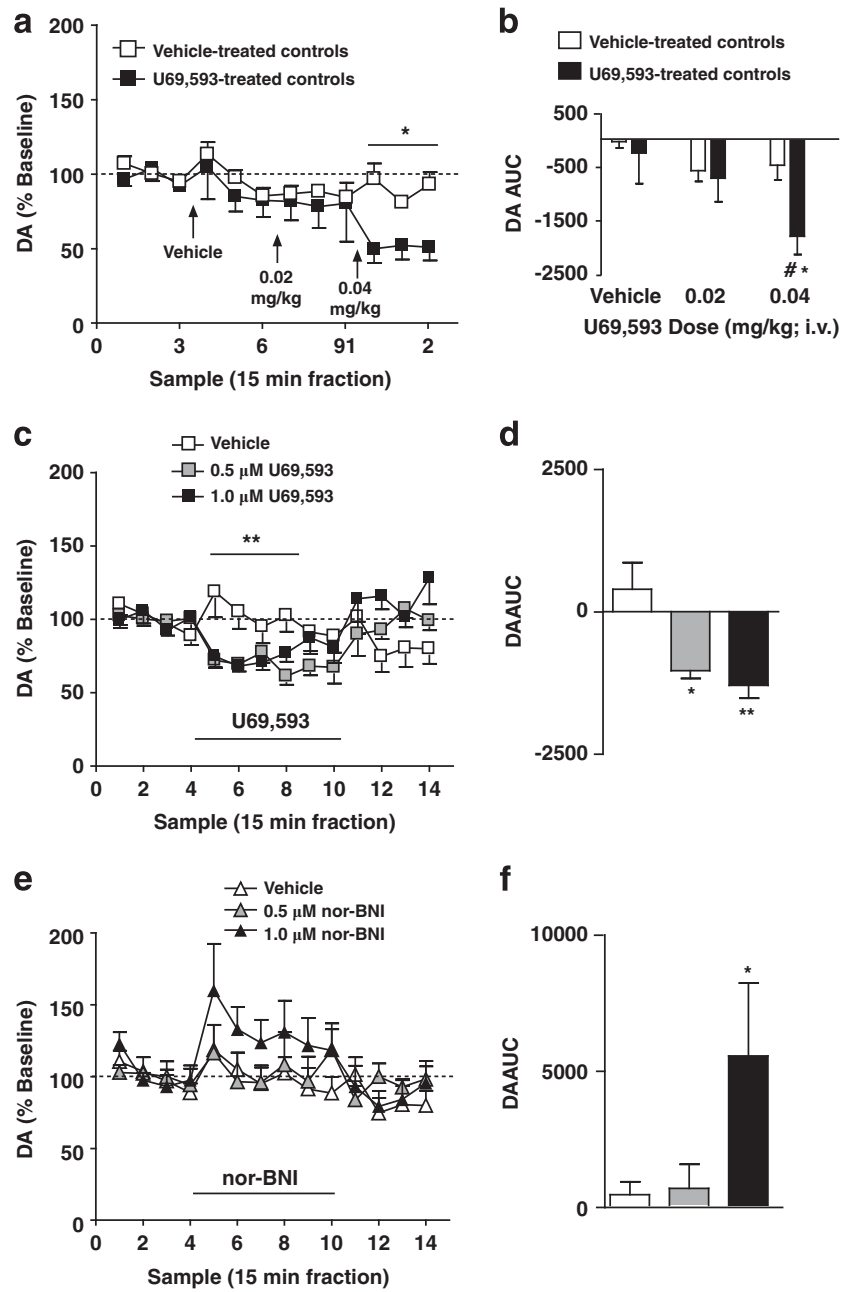

f
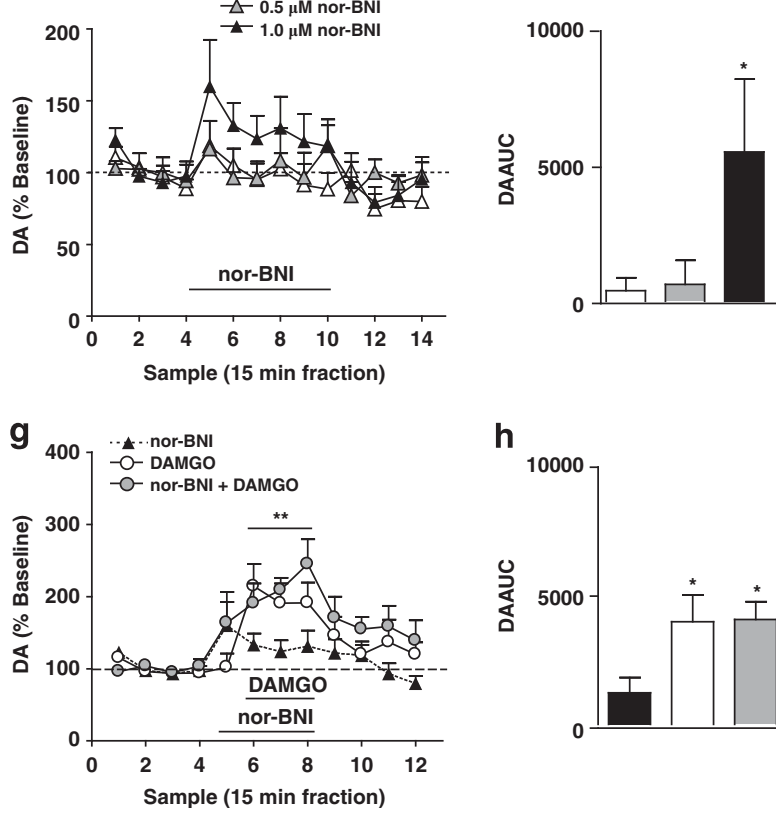

measures ANOVA revealed an effect of sample-type (baseline, nor-BNI, washout; $\mathrm{F}_{(2,108)}=6.80 ; P=0.013$; Figure 1e), but no main effect of dose $\left(\mathrm{F}_{(2,108)}=1.73 ; P=0.21\right)$ or sample-type $\mathrm{x}$ dose interaction $\left(\mathrm{F}_{(4,108)}=1.53 ; P=0.22\right)$. ANOVA comparing AUC values (of the first three nor-BNI samples) across nor-BNI doses revealed an effect of dose $\left(\mathrm{F}_{(2,20)}=3.709 ; \quad P=0.045 ;\right.$ Figure 1f). Post-hoc analysis showed that reverse dialysis of $1.0 \mu \mathrm{M}$ nor-BNI enhanced extracellular DA levels relative to aCSF controls $(P<0.05)$. These results indicate that $\mathrm{mPFC}$ KORs negatively modulates mPFC extracellular DA levels and this system is tonically active.

Nor-BNI may initially act as a functional MOR antagonist (Endoh et al, 1992). Nor-BNI failed to antagonize the effects of intra-mPFC perfusion of the selective MOR agonist, DAMGO $(100 \mu \mathrm{M})$, on DA overflow in rats. Analysis revealed a main effect of sample-type (baseline, nor-BNI and/or DAMGO infusion; $\mathrm{F}_{(1,34)}=30.504 ; \quad P<0.001$; Figure 1g), no main effect of treatment (nor-BNI alone, DAMGO alone, nor-BNI/DAMGO; $\left.\mathrm{F}_{(2,17)}=0.87 ; P=0.44\right)$ or sample-type $\mathrm{X}$ treatment interaction $\left(\mathrm{F}_{(2,34)}=0.66\right.$; $P=0.53)$. ANOVA comparing AUC values across different treatments during the three sample period corresponding to DAMGO infusion, revealed an effect of treatment $\left(\mathrm{F}_{(2,20)}=3.709 ; \quad P=0.045 ;\right.$ Figure $\left.1 \mathrm{~h}\right)$, with significantly enhanced DA in DAMGO and nor-BNI/DAMGO groups relative to nor-BNI alone $(p<0.05)$. Thus, nor-BNI does not enhance DA via MOR antagonism.

\section{mPFC KORs do not Regulate Mesocortical DA Uptake}

$\mathrm{U} 69,593(100 \mathrm{nM})$ administration did not modify total $\left[{ }^{3} \mathrm{H}\right]$ DA uptake in mPFC synaptosomes $\left(t_{24}=0.339\right.$, NS; Supplementary Table $S 1$ ) in rats. Administration of

Figure I mPFC KORs tonically inhibit local DA overflow. (a) Time course of mPFC dialysate DA levels after repeated challenge with systemic administration of vehicle (open squares; $n=7$ ) or escalating doses of U69,593 (filled squares; $n=7$ ). Vertical arrows depict the time of vechicle or $U 69,593(0.02 \mathrm{mg} / \mathrm{kg}$ then subsequently $0.04 \mathrm{mg} / \mathrm{kg})$. *Reflects a significant sample-type $\times$ treatment interaction. (b) AUC values of DA levels after vehicle or U69,593 challenge in control (open bars) and U69,593-treated (filled bars) groups. *and \# reflect a significant difference from baseline and from vehicle controls after intravenous administration of $0.04 \mathrm{mg} / \mathrm{kg}$ at that corresponding time point, respectively. (c) Time course of mPFC dialysate DA levels after reverse dialysis administration of vehicle (white squares; $n=8$ ), $0.5 \mu \mathrm{M} \cup 69,593$ (gray squares; $n=8$ ), or $1.0 \mu \mathrm{M}$ U69,593 (black squares; $n=8$ ). ** Reflects a significant sample-type $\times$ treatment interaction. (d) AUC values of DA levels after vehicle or U69,593 challenge. *and **reflect a significant difference from vehicle controls. (e) Time course of mPFC dialysate DA levels after reverse dialysis administration of vehicle (white triangles; $n=8$ ), $0.5 \mu \mathrm{M}$ nor-BNI (gray triangles; $n=7$ ), or I.0 $\mu \mathrm{M}$ nor-BNI (black triangles; $n=6$ ). (f) AUC values of DA levels after vehicle or nor-BNI challenge. *Reflects a significant difference from vehicle controls. (g) Time course of mPFC DA overflow after reverse dialysis administration of $1.0 \mu \mathrm{M}$ nor-BNI (black triangles; $n=6$ ), $100 \mu \mathrm{M}$ DAMGO (white squares; $n=6$ ), or $100 \mu \mathrm{M}$ DAMGO/ I.0 $\mathrm{MM}$ nor-BNI (black squares; $n=8$ ). **Reflects a main effect of sampletype. (h) AUC values of DA overflow after nor-BNI and/or DAMGO challenge. *Reflects a significant difference from rats challenged with nor-BNI alone. (a, c, e, g) Abscissa, microdialysis fractions (I5 min). Data points reflect the mean \pm SEM. Black bar depicts period of infusion of the indicated drug. 

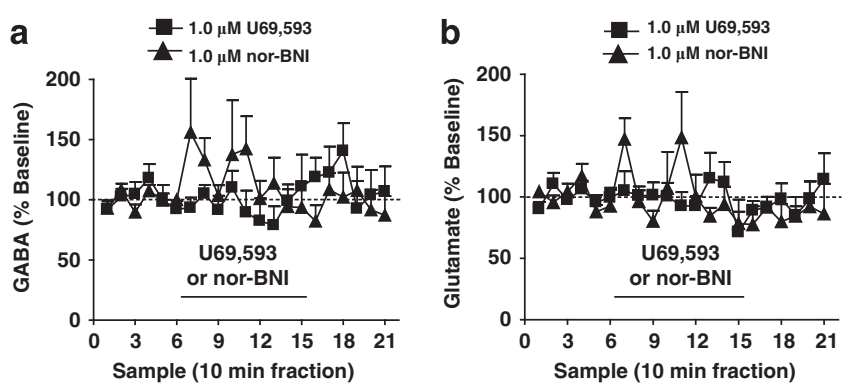

C

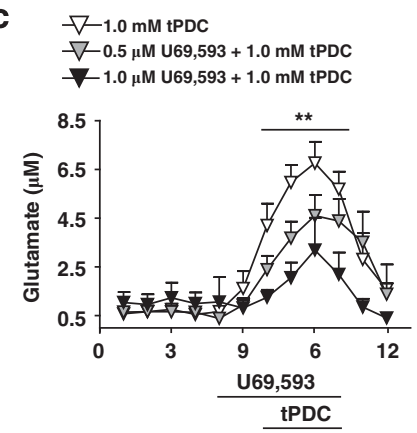

d

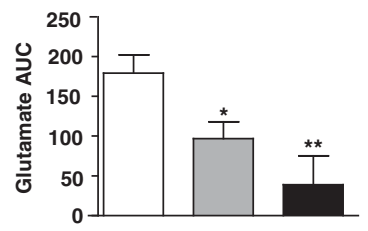

Sample (10 $\mathrm{min}$ fraction)

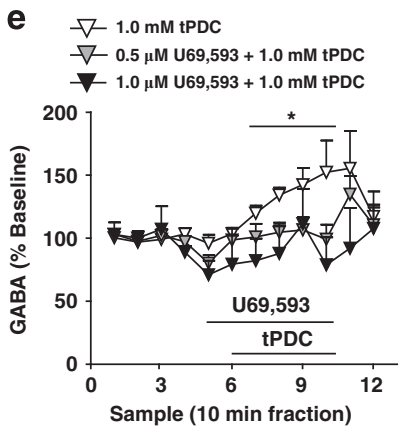

f
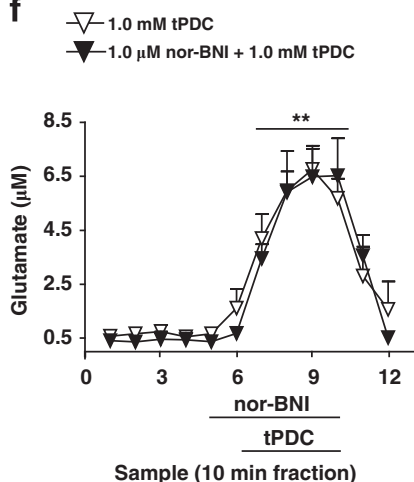

Figure $2 \mathrm{mPFC}$ KORs inhibit tPDC-evoked elevations in extracellular glutamate and glutamate-driven enhancements in extracellular GABA in rats. (a) Time course of basal mPFC extracellular GABA levels after reverse dialysis administration of $1.0 \mu \mathrm{M} \cup 69,593$ (filled squares; $n=10$ ) or $1.0 \mu \mathrm{M}$ nor-BNI (filled triangles; $n=6$ ). (b) Time course of mPFC basal dialysate glutamate levels after reverse dialysis administration of 1.0 $\mu \mathrm{M} \cup 69,593$ (filled squares; $n=10$ ) or $1.0 \mu \mathrm{M}$ nor-BNI (filled triangles; $n=6$ ). (c) Time course of mPFC extracellular glutamate levels in response to local administration of tPDC in rats pretreated with vehicle (white triangles; $n=8$ ), $0.5 \mu \mathrm{M} \cup 69,593$ (gray triangles; $n=8$ ), or $1.0 \mu \mathrm{M} \cup 69,593$ (black triangles; $n=4)$. **Reflects a significant sample-type $\times$ treatment interaction. (d) AUC values of tPDC-evoked elevations in dialysate glutamate levels after vehicle, $0.5 \mu \mathrm{M} \cup 69,593$, or $1.0 \mu \mathrm{M}$ U69,593 pretreatment. *and **reflect a significant difference from vehicle controls. (e) Time course of MPFC GABA dialysate levels in response reverse dialysis of tPDC in animals pretreated with vehicle (white triangles; $n=8$ ), $0.5 \mu \mathrm{M} \cup 69,593$ (gray triangles; $n=8$ ), or I.0 $\mu$ M U69,593 (black triangles; $n=4$ ). *Reflects a significant sample-type $\times$ treatment interaction. ( $f$ ) Time course of mPFC extracellular glutamate levels in response to local administration of tPDC in rats pretreated with vehicle (white triangles; $n=8$ ) or I. $0 \mu \mathrm{M}$ nor-BNI (gray triangles; $n=6$ ). Data points reflect the mean \pm SEM. Black bar depicts period of infusion of the indicated drug.

$\mathrm{U} 69,593$ to $\mathrm{mPFC}$ synaptosomes in the presence of a NET (nisoxetine) or DAT (GBR 12909) blocker failed to alter DAT- or NET-mediated DA uptake, respectively, (DATmediated $t_{24}=0.468$, NS; NET-mediated $t_{24}=0.563$, NS).

\section{mPFC KORs Inhibit Glutamate Overflow and Glutamate-Driven GABA Overflow}

Intra-mPFC perfusion of U69,593 $(1 \mu \mathrm{M})$ and nor-BNI $(1 \mu \mathrm{M})$ were without effect on local glutamate and GABA overflow in rats (Figure 2a and b). Analysis of extracellular glutamate did not reveal a main effect of sample-type (ie, baseline, drug infusion, washout samples; $\mathrm{F}_{(2,140)}=2.672$; $P=0.087)$, treatment $\left(\mathrm{U} 69,593\right.$ or nor-BNI; $\mathrm{F}_{(1,14)}=0.27$; $P=0.87)$, or a sample-type $\mathrm{x}$ treatment interaction $\left(\mathrm{F}_{(2,140)}=1.093 ; P=0.349\right)$. Analysis of extracellular GABA did not reveal a main effect of sample-type (ie, baseline, drug infusion, washout samples; $\left.\mathrm{F}_{(2,140)}=0.947 ; P=0.401\right)$, treatment $\left(\mathrm{F}_{(1,14)}=0.108 ; P=0.748\right)$, or a sample-type $\mathrm{x}$ treatment interaction $\left(\mathrm{F}_{(2,140)}=2.456 ; P=0.105\right)$.

Extracellular glutamate levels are buffered by rapid reuptake potentially masking inhibitory effects of KORs (Herrera-Marschitz et al, 1996; Rawls and McGinty, 1997). The glutamate reuptake blocker tPDC produces TTX- and $\mathrm{Ca}^{2+}$-sensitive elevations in dialysate glutamate (HerreraMarschitz et al, 1996; Rawls and McGinty, 1997; Kreuter et al, 2004). Intra-mPFC perfusion of U69,593 (0.5 and $1.0 \mu \mathrm{M})$ decreased tPDC-induced elevation in dialysate glutamate in rats (Figure $2 \mathrm{c}$ and $\mathrm{d}$ ). Repeated measures ANOVA revealed a main effect of sample-type (baseline, tPDC perfusion period; $\left.\mathrm{F}_{(1,51)}=50.368 ; P<0.001\right)$, no main effect of treatment (tPDC alone, 0.5 or $1.0 \mu \mathrm{M}$ U69,593/ tPDC; $\left.F_{(1,51)}=2.371 ; P=0.124\right)$, and a significant sampletype $\mathrm{x}$ treatment interaction $\left(\mathrm{F}_{(2,51)}=7.066 ; P=0.006\right)$. ANOVA of AUC values (of the tPDC sample period) revealed an effect of treatment $\left(\mathrm{F}_{(2,19)}=6.984 ; P=0.006\right.$; Figure 2d). Post-hoc analysis revealed that both reverse dialysis of 0.5 and $1.0 \mu \mathrm{M}$ U69,593 attenuated tPDC-evoked glutamate levels $(P<0.05)$. Interestingly, tPDC also elevated extracellular GABA levels, an effect blocked by 0.5 and $1.0 \mu \mathrm{M}$ U69,593 pretreatment (Figure 2e). Repeated measures of ANOVA showed no main effect of sample-type (baseline, $\mathrm{tPDC}$ perfusion period; $\mathrm{F}_{(1,51)}=1.265 ; P=0.276$ ), a main effect of treatment (tPDC alone, 0.5 or $1.0 \mu \mathrm{M}$ $\left.\mathrm{U} 69,593 / \mathrm{tPDC} ; \mathrm{F}_{(2,17)}=4.343 ; P=0.03\right)$, and a sample-type $\mathrm{x}$ treatment interaction $\left(\mathrm{F}_{(2,51)}=4.492 ; P=0.027\right)$. Nor-BNI infusion $(1.0 \mu \mathrm{M})$ in the presence of the glutamate reuptake blocker tPDC, failed to modify the tPDC-induced extracellular glutamate response (Figure 2f). Thus, mPFC KORs inhibit local glutamate overflow, and prevent glutamateinduced elevations in extracellular GABA levels.

\section{mPFC KORs Inhibit Presynaptic Glutamate Release onto mPFC Pyramidal Neurons}

Bath application of U69,593 $(1 \mu \mathrm{M})$ decreased CNQX/APVsensitive mEPSP frequency, but not amplitude in rats (Figure 3a-e). U69,593 decreased mEPSP frequency $\left(t_{8}=3.935 ; \quad P<0.01\right.$; Figure $\left.3 \mathrm{a}-\mathrm{c}\right)$. mEPSP amplitude did not differ significantly before and after U69,593 administration (Figure $3 \mathrm{~d}$ and e). The decrease in mEPSP frequency was not observed in cells treated with physiological aCSF $\left(t_{6}=1.934 ; P=0.101 ;\right.$ Figure $\left.3 \mathrm{f}\right)$. Using picrotoxin to isolate CNQX/APV-sensitive synapses, U69,593 decreased mEPSP frequency $\left(t_{10}=2.381 ; P<0.05\right.$; Figure $\left.3 \mathrm{~g}\right)$. Pretreatment with nor-BNI $(0.1 \mu \mathrm{M})$ blocked U69,593-induced decrease of mEPSP frequency $\left(t_{6}=0.939 ; P=0.384\right.$; Figure $\left.3 \mathrm{~h}\right)$. 
a
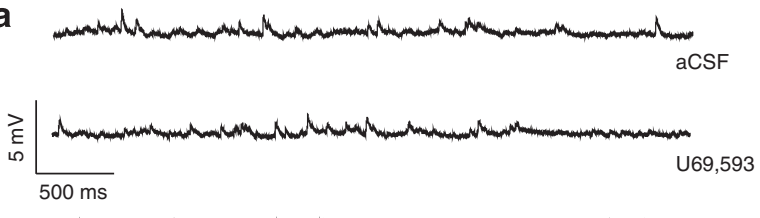

$C N Q X+A P V$
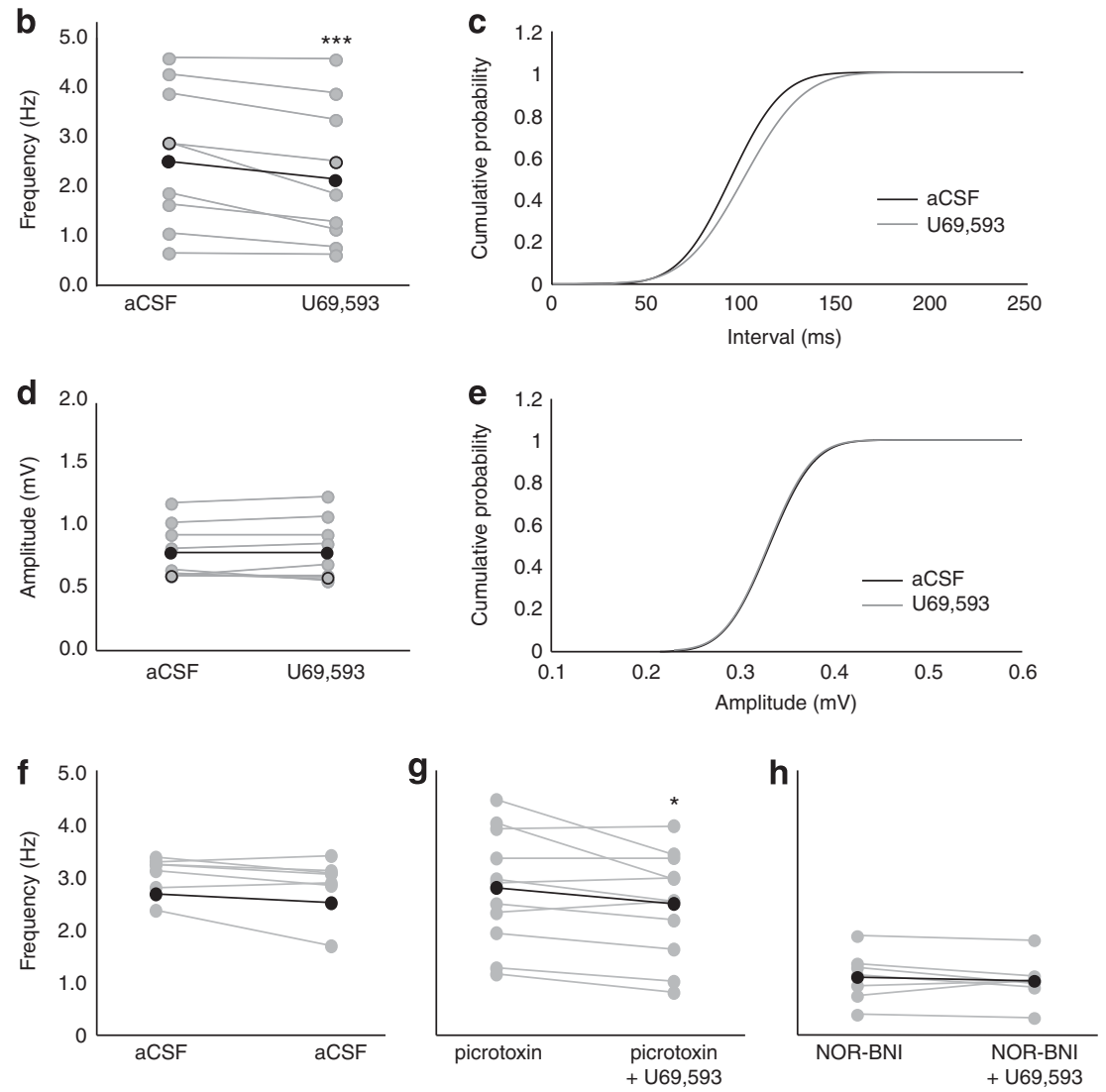

Figure $3 \mathrm{mPFC}$ KORs inhibit presynaptic glutamate release in rats. (a) Representative trace depicting glutamatergic CNQX/APV-sensitive mEPSPs before (top) and after (middle) bath application of U69,593 (I.0 $\mu \mathrm{M}$ ). CNQX/APV bath application abolished the presence of all mEPSPs (bottom). (b, c) mEPSP frequency, but not amplitude $(d, e)$ is decreased after U69,593 application in the presence of physiological aCSF ( $n=9$ cells from four animals). **** Reflect a significant difference in mEPSP frequency after U69,593 application relative to baseline. Open circles indicate example trace. Black circles indicate the mean. $(f)$ These effects are not observed in cells treated with physiological aCSF ( $n=7$ cells from two animals). (g) In the presence of picrotoxin, U69,593 similarly decreases mEPSP frequency ( $n=1$ I cells from five animals). *Reflect a significant difference in mEPSP frequency after U69,593 application relative to baseline. (h) Nor-BNI $(0.1 \mu \mathrm{M})$ pretreatment blocks U69,593-induced decreases in mEPSP frequency ( $n=7$ cells from three animals) in the presence of normal aCSF.

These results suggest that KORs inhibit presynaptic glutamate release.

We subsequently conducted an ANOVA of baseline mEPSP frequency in the aCSF controls (both treated with subsequent aCSF or U69,593), nor-BNI-pretreated, and picrotoxin-pretreated cells. ANOVA revealed an effect of treatment $\left(\mathrm{F}_{(2,25)}=13.97 ; P<0.001\right)$, with nor-BNI pretreated cells showing decreased mEPSP frequency relative to aCSF- and picrotoxin-treated cells $(P<0.05)$. This suggests that nor-BNI pretreatment decreased presynaptic glutamate release, however, the mechanism by which this occurs is not clear. Nor-BNI-induced decreased mEPSP frequency by nor-BNI may potentially occlude any inhibitory effects produced by U69,593. To determine whether this explained the lack of a U69,593 effect in nor-BNItreated cells, we conducted a $t$-test in a subset of cells with a low mEPSP frequency. In these cells, a significant decrease in mEPSP frequency in response to U69,593 is still observed $\left(t_{(6)}=4.449 ; P=0.0043\right.$; data not shown), suggesting that nor-BNI did not occlude the U69,593-mediated inhibition of mEPSP frequency by producing a floor effect.

\section{KORs on mPFC DA Terminals Directly Inhibit mPFC DA Overflow}

No-net-flux microdialysis experiments revealed no difference in basal DA dynamics between control and DAT-KOR $\mathrm{KO}$ mice in $E_{\mathrm{d}}$ (Figure $4 \mathrm{c} ; t_{16}=-0.533$, NS) or mPFC $\mathrm{DA}_{\text {ext }}$ (Figure $4 \mathrm{~d} ; t_{24}=0.011$, NS). However, reverse dialysis of U69,593 inhibited mPFC DA overflow in control mice, an effect that was absent in DAT-KOR $\mathrm{KO}$ mice (Figure $4 \mathrm{e}$ and $\mathrm{f}$ ). Analysis revealed a sample-type (baseline, U69,593 infusion, washout) $\mathrm{x}$ genotype (control and DAT-KOR KO) interaction 
a

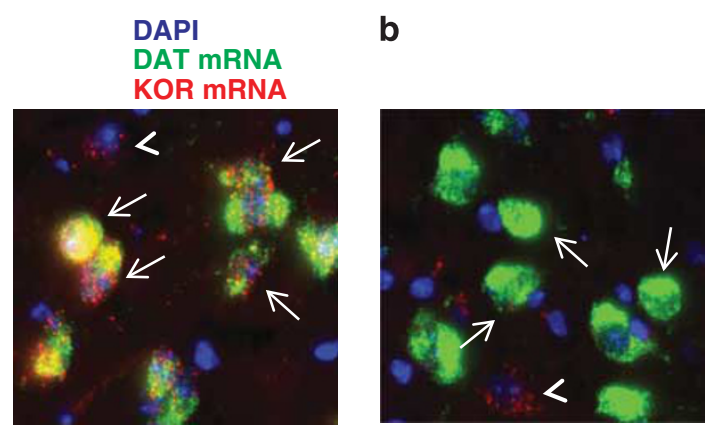

C

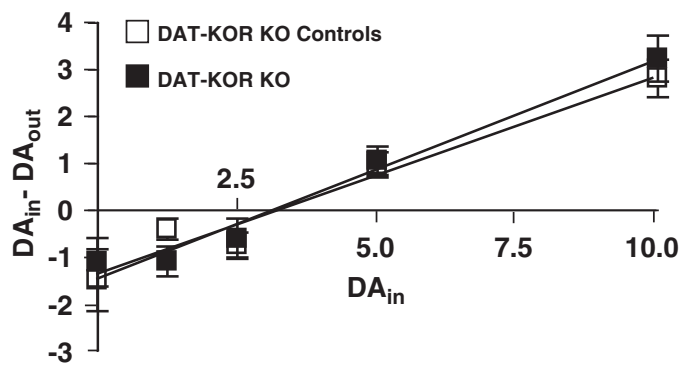

d
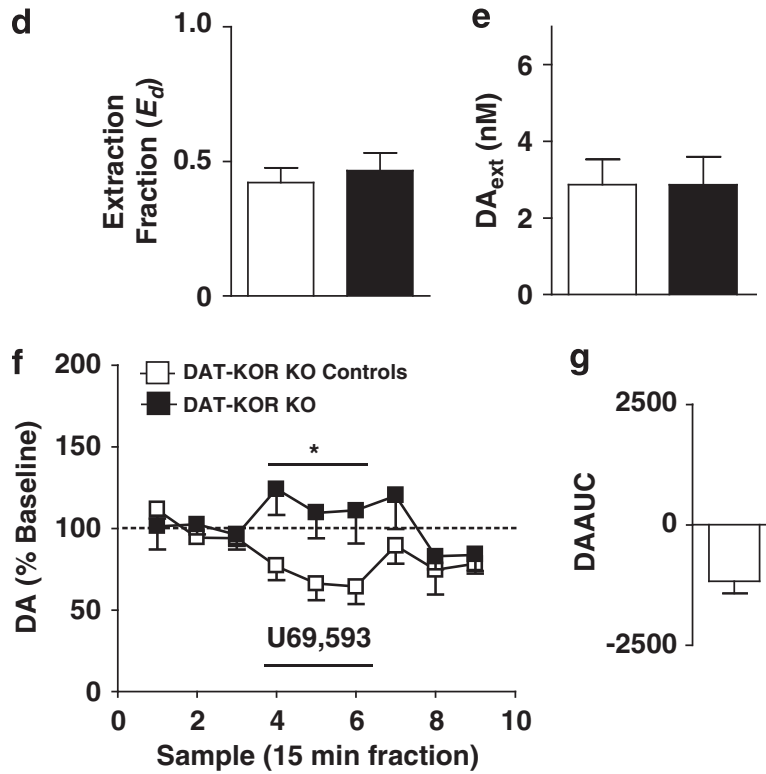

g

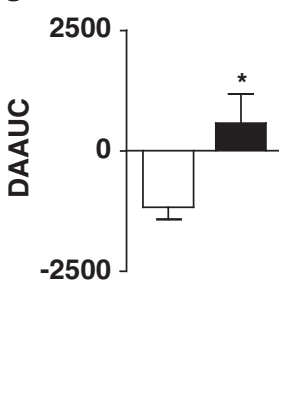

Figure 4 mPFC KOR activation inhibits local extracellular DA levels via direct activation KORs on DA varicosities in mice. (a, b) Representative images of dual fluorescence in situ hybridization of DAT mRNA (green) and KOR mRNA (red) in the VTA of a control (a) and DAT-KOR KO (b) mouse. Blue, green, and red signals represent DAPI nucleic acid stain, DAT $m R N A$, and KOR mRNA, respectively. Arrows indicate cells expressing DAT mRNA. DAT-positive neurons co-express KOR mRNA in control animals (a). As predicted DAT-positive neurons do not express KOR mRNA in DAT-KOR KO mice (b). Additionally, KOR mRNA was present in DAT-negative neurons in both control and $\mathrm{KO}$ animals (arrowheads in $\mathrm{a}, \mathrm{b}$ ). (c) $D A_{\text {in }}-D A_{\text {out }}$ plotted against $D A_{\text {in }}$ with fitted regression lines for control (open squares; $n=9$ ) and DAT-KOR KO (filled squares; $n=9$ ) mice depicting similar $x$ intercepts $\left(D A_{\text {ext }}\right)$ and slopes $\left(E_{d}\right)$. (d) $E_{d}$ (an indirect measure of DA uptake) in control (open bar) and DAT-KOR KO (filled bar) mice. (e) mPFC DA ext in control (open bar) and DAT-KOR KO (filled bar) mice. (f) Time course of mPFC dialysate DA levels after reverse dialysis administration of I.0 $\mathrm{MM} \cup 69,593$ in control (open squares; $n=6$ ) and DATKOR KO (filled squares; $n=5$ ) mice. *Reflects a significant sample-type x-treatment interaction. (g) AUC values of DA levels after I.0 $\mu$ M U69,593 challenge in control (open bar) and DAT-KOR KO (filled bar) mice. *Reflects a significant difference from control mice. Data points reflect the mean \pm SEM. Black bar depicts period of infusion of the indicated drug.
(Figure 4e; $\left.\mathrm{F}_{(2,36)}=3.825 ; P=0.041\right)$. Comparison of AUC values (of the first three U69,593 samples) revealed a significant difference between the control and DAT-KOR KO mice (Figure 4f; $t_{9}=2.867, P=0.019$ ). Thus, U69,593 inhibits mPFC DA levels by acting on MPFC DA varicosity KORs. This also provides functional evidence that DATKOR KO mice lack functional KORs in mesocortical DA terminals.

\section{mPFC KOR Signaling is Necessary for KOR-Mediated Aversion}

Intra-mPFC microinjection of a KOR agonist produces $\mathrm{CPA}$ (Bals-Kubik et al, 1993). We hypothesized that mPFC KOR signaling is necessary for KOR-mediated CPA in rats. We predicted that intra-mPFC nor-BNI $(5 \mu \mathrm{g} / 0.5 \mu \mathrm{l})$ would block the ability of systemic U69,593 $(0.32 \mathrm{mg} / \mathrm{kg}$; sc) to produce CPA (Figure 5c). A-priori planned comparisons demonstrated that U69,593 decreased time spent in the U69,593-paired chamber in aCSF-treated rats during the post-test relative to the pre-test $(P<0.01)$, an effect not apparent in aCSF- and nor-BNI-treated rats conditioned with vehicle. Intra-mPFC nor-BNI-treated rats conditioned with $U 69,593$ did not display a significant decrease in the time spent in the U69,593-paired compartment during the post-test relative to the pre-test. aCSF-treated rats conditioned with U69,593 spent less time in the U69,593-paired compartment during post-testing relative to nor-BNItreated counterparts $(P<0.01)$. Bilateral guide cannula tips were primarily located in the dorsal mPFC including the prelimbic cortex and ventral anterior cingulate cortex (Figure 5a).

\section{DISCUSSION}

Systemic administration of a KOR agonist inhibited mesocortical DA transmission. Activation and blockade of mPFC KORs inhibited and enhanced local DA overflow, respectively. DA uptake was unaffected by KOR activation. Utilizing mice lacking KOR in DA neurons, we confirmed that mPFC KOR inhibition of local DA levels is via direct action on DA terminals. Thus, KOR inhibition of DA is tonically active and is due to inhibition of DA release by KORs on mPFC DA terminals. mPFC KOR activation attenuated tPDC-induced elevations in glutamate and GABA. Whole-cell recordings demonstrated that KOR activation decreased glutamatergic mEPSP frequency, but not amplitude, suggesting a presynaptic site of action. U69,593-mediated CPA was abolished by intra-mPFC KOR blockade, indicating mPFC KOR signaling is necessary for KOR-mediated aversion.

Here, we provide evidence that mesocortical DA neurotransmission is directly and negatively modulated by mPFC KOR systems. mPFC DA overflow was inhibited by systemic U69,593 administration. mPFC-projecting VTA DA neurons are hyperpolarized by U69,593, resulting in decreased $\mathrm{mPFC}$ DA levels (Margolis et al, 2006). As KORs are also found on axonal varicosities in mPFC (Svingos and Colago, 2002), we determined the role of local KORs in modulating local DA levels. mPFC extracellular DA levels were reduced by reverse dialysis administration of U69,593 and enhanced 
a

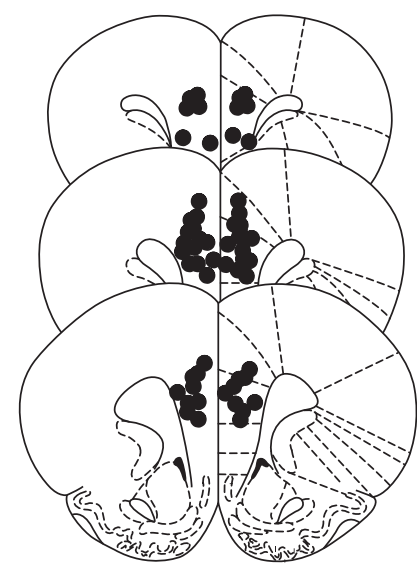

b
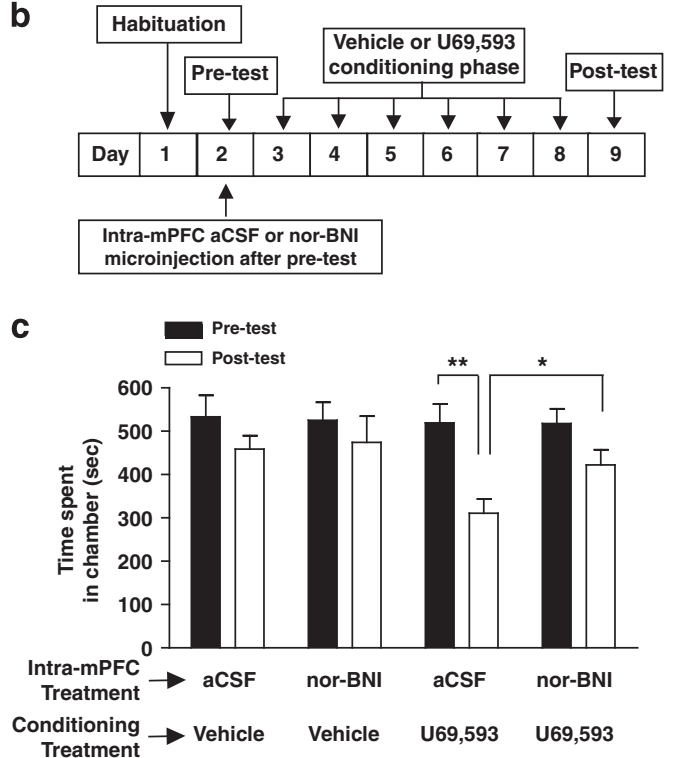

Figure 5 mPFC KOR signaling is necessary for KOR-mediated CPA in rats. (a) Placements of guide cannulae microinjector tips (black dots) in the mPFC. Diagrams were adapted from Paxinos and Watson (1987). (b) Schema depicting CPA procedures. Rats were implanted with guide cannula 4 to 5 days before CPA procedures. In CPA procedures, rats are initially tested for their preference (pre-test). Rats were divided into one of four sub-groups: aCSF/ vehicle $(n=6)$, nor-BNI/vehicle $(n=6)$, aCSF/U69,593 $(n=9)$, or nor-BNI/U69,593 $(n=12)$. Rats received intra-mPFC aCSF or nor-BNI $(5 \mu \mathrm{g} / 0.5 \mu \mathrm{l})$ microinjections 3-5 h after CPA pre-test. During the conditioning phase, the initially preferred compartment of the conditioning apparatus is paired with systemic vehicle or $U 69,593$ administration $(0.32 \mathrm{mg} / \mathrm{kg})$, while the other compartment is paired with vehicle on the subsequent day. This 2 -day procedure is repeated three times over 6 consecutive days of conditioning. Conditioned drug effects are assayed on the post-test day when rats are allowed access to both compartments in a drug-free state. (c) Time spent in the U69,593-paired compartment during the pre-test (black bar) and post-test (white bar) of CPA procedures. ***eflects a significant difference in the time-spent in the U69,593-paired compartment during the post-test relative to the pre-test in rats microinjected with intra-mPFC aCSF. This effect was not observed in rats treated with intra-mPFC nor-BNI that were similarly conditioned with U69,593 and rats that were conditioned with vehicle. *Reflects a significant difference in the time-spent in the U69,593-paired compartment during the post-test between intra-mPFC aCSF-treated and nor-BNI-treated rats. Data points reflect the mean \pm SEM.

by nor-BNI. This is consistent with findings that KOR activation decreases DA efflux in frontal cortex synaptosomes and slices (Heijna et al, 1990; Grilli et al, 2009). mPFC KOR activation may alter local DA tone indirectly by modulating other systems regulating DA terminals and/or DA neuron activity. To elucidate if KORs on DA terminals mediate inhibition of DA by intra-mPFC U69,593, we determined whether intra-mPFC U69,593-induced decreases in local DA levels were altered in DAT-KOR KO mice. U69,593 inhibited mPFC DA levels in control mice, an effect that was absent in DAT-KOR KO mice. Thus, mPFC KORmediated inhibition of DA overflow is governed by KORs on DA varicosities.

The inhibitory effects of KOR agonists on extracellular DA levels are attributed to KOR-mediated inhibition of DA release (Spanagel et al, 1992). However, work from our laboratory has demonstrated that KOR signaling in the NAcc upregulates DAT function in vivo (Thompson et al, 2000; Chefer et al, 2005). In mPFC synaptosomes U69,593 failed to modify total DA uptake, DAT-, and NET-mediated DA uptake. Collectively, these results suggest that KORs on DA terminals in the mPFC tonically decrease extracellular DA levels by decreasing DA release. As there is no difference in extracellular DA levels and uptake in controls and DAT-KOR KO mice, it is likely that release is unaltered. This suggests that developmental compensation in MPFC DA dynamics occurs in absence of a functioning mesocortical KOR system.
KOR systems differentially regulate mesolimbic and mesocortical DA pathways. Activation of VTA KORs reduces $\mathrm{mPFC}$ (Margolis et al, 2006), but not NAcc, DA levels (Spanagel et al, 1992; Devine et al, 1993; Margolis et al, 2006). Both NAcc and mPFC DA overflow is tonically inhibited by local KORs (Spanagel et al, 1992). However, in the NAcc KORs decrease DA tone by inhibiting DA release and increasing DA uptake (Thompson et al, 2000; Chefer et al, 2005), whereas mPFC KORs do not alter DA uptake. Although mesocortical DA systems are inhibited by VTA and mPFC KORs, only mPFC KORs are tonically active. KOR system recruitment may differentially shape mesocortical and mesoaccumbal DA responses, depending on where dynorphins are released (ie, cell bodies $v s$ terminal regions) or whether tonic KOR activity exists (ie, in DA terminals).

We found that KOR activation inhibits presynaptic glutamatergic function in vitro and in vivo. Basal, dialysate mPFC glutamate levels, which are not TTX-sensitive or $\mathrm{Ca}^{2+}$ channel-sensitive (Melendez et al, 2005), were unaltered by U69,593. tPDC-evoked elevations in extracellular glutamate are TTX-sensitive and $\mathrm{Ca}^{2+}$-dependent (Herrera-Marschitz et al, 1996; Rawls and McGinty, 1997; Kreuter et al, 2004), suggesting tPDC reveals synaptic sources of extracellular glutamate. tPDC has been utilized to unmask the inhibitory effects of U69,593 on striatal glutamate (Rawls and McGinty, 1998). An inhibitory role of KOR on synaptic glutamate transmission was demonstrated using whole-cell recordings where U69,593 
produced a decrease in mEPSP frequency, but not amplitude, in a nor-BNI-sensitive manner. This suggests KORs inhibit glutamate release via a presynaptic site of action and is consistent with previous findings. KOR immunoreactivity has been localized to presynaptic terminals of excitatory synapses (Svingos and Colago, 2002). Dynorphin either enhances or decreases electrically evoked EPSPs, but not EPSPs evoked by iontophoretically applied glutamate (Sutor and Zieglgansberger, 1984). KOR activation inhibits $\mathrm{K}^{+}$-stimulated glutamate release from $\mathrm{mPFC}$ synaptosomes (Sbrenna et al, 1999). Prefrontal pyramidal neurons and interneurons are innervated by limbic, thalamic, and cortical glutamatergic afferents. However, it is not clear which glutamatergic MPFC inputs are inhibited by KORs, as limbic and thalamic efferent regions are rich in KOR mRNA (Meng et al, 1993). As a proportion of DA neurons co-release glutamate (Yamaguchi et al, 2011) and KORs directly inhibit DA varicosities, KORs may be inhibiting these sources of glutamate.

Intra-mPFC KOR activation is sufficient to produce CPA (Bals-Kubik et al, 1993). As systemically administered KOR agonists act at various neural loci to produce CPA, we assessed whether mPFC KOR activation was necessary for KOR-mediated aversion. mPFC nor-BNI microinjection blocked CPA produced by systemically administered U69,593. As mPFC KOR signaling is necessary for KORmediated aversion, KOR signaling in the MPFC may encode alterations in affect, stress/anxiety-like behavior, and/or brain reward function. Infralimbic U69,593 or nor-BNI microinjections produce anxiolytic and anxiogenic effects in mice, respectively, (Wall and Messier, 2000, 2002). Considering prelimbic and infralimbic cortices have divergent roles in reward-seeking behavior and fear (Peters et al, 2009), it is plausible that prelimbic KOR signaling encodes opposite behavioral effects as infralimbic. This is consistent with the present study where dorsal mPFC microinjections of nor-BNI focused on the prelimbic/ ventral anterior cingulate cortex blocked KOR-mediated $\mathrm{CPA}$. The question remains whether KOR modulation of mPFC excitation/inhibition, and not DA, mediates this aversive effect, as mesocortical DA denervation does not modify KOR-mediated aversion (Shippenberg et al, 1993).

Although KORs can inhibit mPFC DA, glutamate, and glutamate-driven GABA enhancements, it is currently not clear how KORs ultimately modulate cortical network activity. DA bi-directionally modulates GABAergic and glutamatergic amino-acid transmission (Seamans and Yang, 2004). KORs may have complex effects on information processing in cortical circuits by altering GABA/ glutamate interactions and decreasing DA modulation. This is evident in EEG recordings in humans and rats where systemic KOR agonists decrease spectral power in oscillations at various frequencies (Young and Khazan, 1984; Ranganathan et al, 2012). Understanding the role of mPFC KOR signaling in information processing in cortical networks may reveal an understanding of processes underlying behavioral effects of KOR ligands. KORs may provide a therapeutic target for ameliorating abnormal mood/emotion and cognitive deficits in psychiatric disorders associated with altered prefrontal cortical neural activity.

\section{ACKNOWLEDGEMENTS}

This work was supported by the National Institute on Drug Abuse Intramural Research Program, grants from the National Institutes of Health (PO, MH57683; TSS and SR, MH083928), a National Science Foundation Graduate Research Fellowship (HAT), a Meyerhoff Graduate Fellowship (HAT), and a Ford Foundation Predoctoral Fellowship (HAT). The authors would like to thank Dr Jennifer Whistler for her generous donation of the KOR ${ }^{\text {loxp }}$ mice. The authors would like to thank Drs Brad Alger, Antonello Bonci, Joe Cheer, and Greg Elmer for their helpful comments and discussion.

\section{DISCLOSURE}

Dr Patricio O'Donnell receives compensation as a consultant for Roche Pharmaceuticals. All remaining authors declare no have conflict of interest.

\section{AUTHOR CONTRIBUTION}

HAT, KNS-K, and VC performed microdialysis experiments. HAT and EO executed conditioning experiments. $\mathrm{CMB}$ performed genotyping and FISH experiments using transgenic animals. DS performed electrophysiology experiments. SR performed dopamine uptake studies. HAT, VC and DS analyzed the results. HAT, VC, PO, and TS designed the study. HAT, VC, and PO wrote the manuscript.

\section{REFERENCES}

Backman CM, Malik N, Zhang Y, Shan L, Grinberg A, Hoffer BJ et al (2006). Characterization of a mouse strain expressing Cre recombinase from the $3^{\prime}$ untranslated region of the dopamine transporter locus. Genesis 44: 383-390.

Bals-Kubik R, Ableitner A, Herz A, Shippenberg TS (1993). Neuroanatomical sites mediating the motivational effects of opioids as mapped by the conditioned place preference paradigm in rats. J Pharmacol Exp Ther 264: 489-495.

Bruchas MR, Land BB, Chavkin C (2010). The dynorphin/kappa opioid system as a modulator of stress-induced and proaddictive behaviors. Brain Res 1314: 44-55.

Chefer VI, Denoroy L, Zapata A, Shippenberg TS (2009). Mu opioid receptor modulation of somatodendritic dopamine overflow: GABAergic and glutamatergic mechanisms. Eur J Neurosci 30: 272-278.

Chefer VI, Czyzyk T, Bolan EA, Moron J, Pintar JE, Shippenberg TS (2005). Endogenous kappa-opioid receptor systems regulate mesoaccumbal dopamine dynamics and vulnerability to cocaine. J Neurosci 25: 5029-5037.

Devine DP, Leone P, Pocock D, Wise RA (1993). Differential involvement of ventral tegmental mu, delta and kappa opioid receptors in modulation of basal mesolimbic dopamine release: in vivo microdialysis studies. J Pharmacol Exp Ther 266: 1236-1246.

Endoh T, Matsuura H, Tanaka C, Nagase H (1992). Norbinaltorphimine: a potent and selective kappa-opioid receptor antagonist with long-lasting activity in vivo. Arch Int Pharmacodyn Ther 316: 30-42.

Grilli M, Neri E, Zappettini S, Massa F, Bisio A, Romussi G et al (2009). Salvinorin A exerts opposite presynaptic controls on neurotransmitter exocytosis from mouse brain nerve terminals. Neuropharmacology 57: 523-530. 
Heijna MH, Padt M, Hogenboom F, Portoghese PS, Mulder AH, Schoffelmeer AN (1990). Opioid receptor-mediated inhibition of dopamine and acetylcholine release from slices of rat nucleus accumbens, olfactory tubercle and frontal cortex. Eur $J$ Pharmacol 181: 267-278.

Herrera-Marschitz M, You ZB, Goiny M, Meana JJ, Silveira R, Godukhin OV et al (1996). On the origin of extracellular glutamate levels monitored in the basal ganglia of the rat by in vivo microdialysis. J Neurochem 66: 1726-1735.

Hjelmstad GO, Fields HL (2001). Kappa opioid receptor inhibition of glutamatergic transmission in the nucleus accumbens shell. J Neurophysiol 85: 1153-1158.

Hjelmstad GO, Fields HL (2003). Kappa opioid receptor activation in the nucleus accumbens inhibits glutamate and GABA release through different mechanisms. J Neurophysiol 89: 2389-2395.

Iremonger KJ, Bains JS (2009). Retrograde opioid signaling regulates glutamatergic transmission in the hypothalamus. J Neurosci 29: 7349-7358.

Knoll AT, Carlezon WA Jr. (2010). Dynorphin, stress, and depression. Brain Res 1314: 56-73.

Kreuter JD, Mattson BJ, Wang B, You ZB, Hope BT (2004). Cocaine-induced Fos expression in rat striatum is blocked by chloral hydrate or urethane. Neuroscience 127: 233-242.

Lemos JC, Roth CA, Messinger DI, Gill HK, Phillips PE, Chavkin C (2012). Repeated stress dysregulates $\kappa$-opioid receptor signaling in the dorsal raphe through a p38 $\alpha$ MAPK-dependent mechanism. J Neurosci 32: 12325-12336.

Margolis EB, Hjelmstad GO, Bonci A, Fields HL (2003). Kappaopioid agonists directly inhibit midbrain dopaminergic neurons. J Neurosci 23: 9981-9986.

Margolis EB, Lock H, Chefer VI, Shippenberg TS, Hjelmstad GO, Fields HL (2006). Kappa opioids selectively control dopaminergic neurons projecting to the prefrontal cortex. Proc Natl Acad Sci USA 103: 2938-2942.

Melendez RI, Vuthiganon J, Kalivas PW (2005). Regulation of extracellular glutamate in the prefrontal cortex: focus on the cystine glutamate exchanger and group I metabotropic glutamate receptors. J Pharmacol Exp Ther 314: 139-147.

Meng F, Xie GX, Thompson RC, Mansour A, Goldstein A, Watson SJ et al (1993). Cloning and pharmacological characterization of a rat kappa opioid receptor. Proc Natl Acad Sci USA 90: 9954-9958.

Mu P, Neumann PA, Panksepp J, Schluter OM, Dong Y (2011). Exposure to cocaine alters dynorphin-mediated regulation of excitatory synaptic transmission in nucleus accumbens neurons. Biol Psychiatry 69: 228-235.

Mucha RF, Herz A (1985). Motivational properties of kappa and $\mathrm{mu}$ opioid receptor agonists studied with place and taste preference conditioning. Psychopharmacology 86: 274-280.

Paxinos G, Franklin KBJ (2001). The Mouse Brain in Stereotaxic Coordinates. Academic Press: San Diego.

Paxinos G, Watson C (1998). The Rat Brain in Stereotaxic Coordinates. Academic Press: San Diego.

Peters J, Kalivas PW, Quirk GJ (2009). Extinction circuits for fear and addiction overlap in prefrontal cortex. Learn Mem 16: 279-288.

Pfeiffer A, Brantl V, Herz A, Emrich HM (1986). Psychotomimesis mediated by kappa opiate receptors. Science 233: 774-776.

Ranganathan M, Schnakenberg A, Skosnik PD, Cohen BM, Pittman B, Sewell RA et al (2012). Dose-related behavioral, subjective, endocrine, and psychophysiological effects of the kappa opioid agonist Salvinorin A in humans. Biol Psychiatry 72: 871-879.
Rawls SM, McGinty JF (1997). L-trans-pyrrolidine-2,4-dicarboxylic acid-evoked striatal glutamate levels are attenuated by calcium reduction, tetrodotoxin, and glutamate receptor blockade. J Neurochem 68: 1553-1563.

Rawls SM, McGinty JF (1998). Kappa receptor activation attenuates L-trans-pyrrolidine-2,4-dicarboxylic acid-evoked glutamate levels in the striatum. J Neurochem 70: 626-634.

Sbrenna S, Marti M, Morari M, Calo G, Guerrini R, Beani L et al (1999). L-glutamate and gamma-aminobutyric acid efflux from rat cerebrocortical synaptosomes: modulation by kappa- and mu- but not delta- and opioid receptor like-1 receptors. J Pharmacol Exp Ther 291: 1365-1371.

Seamans JK, Yang CR (2004). The principal features and mechanisms of dopamine modulation in the prefrontal cortex. Prog Neurobiol 74: 1-58.

Shippenberg TS, Bals-Kubik R, Herz A (1993). Examination of the neurochemical substrates mediating the motivational effects of opioids: role of the mesolimbic dopamine system and D-1 vs D-2 dopamine receptors. J Pharmacol Exp Ther 265: 53-59.

Shippenberg TS, Zapata A, Chefer VI (2007). Dynorphin and the pathophysiology of drug addiction. Pharmacol Ther 116: 306-321.

Spanagel R, Herz A, Shippenberg TS (1992). Opposing tonically active endogenous opioid systems modulate the mesolimbic dopaminergic pathway. Proc Natl Acad Sci USA 89: 2046-2050.

Sutor B, Zieglgansberger W (1984). Actions of D-Ala2-D-Leu5enkephalin and dynorphin A (1-17) on neocortical neurons in vitro. Neuropeptides 5: 241-244.

Svingos AL, Colago EE (2002). Kappa-opioid and NMDA glutamate receptors are differentially targeted within rat medial prefrontal cortex. Brain Res 946: 262-271.

Tejeda HA, Shippenberg TS, Henriksson R (2012). The dynorphin/ kappa-opioid receptor system and its role in psychiatric disorders. Cell Mol Life Sci 69: 857-896.

Thompson AC, Zapata A, Justice JB Jr., Vaughan RA, Sharpe LG, Shippenberg TS (2000). Kappa-opioid receptor activation modifies dopamine uptake in the nucleus accumbens and opposes the effects of cocaine. J Neurosci 20: 9333-9340.

Todtenkopf MS, Marcus JF, Portoghese PS, Carlezon WA Jr. (2004). Effects of kappa-opioid receptor ligands on intracranial self-stimulation in rats. Psychopharmacology 172: 463-470.

Wall PM, Messier C (2000). U-69,593 microinjection in the infralimbic cortex reduces anxiety and enhances spontaneous alternation memory in mice. Brain Res 856: 259-280.

Wall PM, Messier C (2002). Infralimbic kappa opioid and muscarinic M1 receptor interactions in the concurrent modulation of anxiety and memory. Psychopharmacology 160: 233-244.

Walsh SL, Strain EC, Abreu ME, Bigelow GE (2001). Enadoline, a selective kappa opioid agonist: comparison with butorphanol and hydromorphone in humans. Psychopharmacology 157: 151-162.

Yamaguchi T, Wang HL, Li X, Ng TH, Morales M (2011). Mesocorticolimbic glutamatergic pathway. J Neurosci 31: 8476-8490.

Young GA, Khazan N (1984). Differential neuropharmacological effects of mu, kappa and sigma opioid agonists on cortical EEG power spectra in the rat. Stereospecificity and naloxone antagonism. Neuropharmacology 23: 1161-1165.

Zapata A, Kivell B, Han Y, Javitch JA, Bolan EA, Kuraguntla D et al (2007). Regulation of dopamine transporter function and cell surface expression by D3 dopamine receptors. J Biol Chem 282: 35842-35854.

Supplementary Information accompanies the paper on the Neuropsychopharmacology website (http://www.nature.com/npp) 